
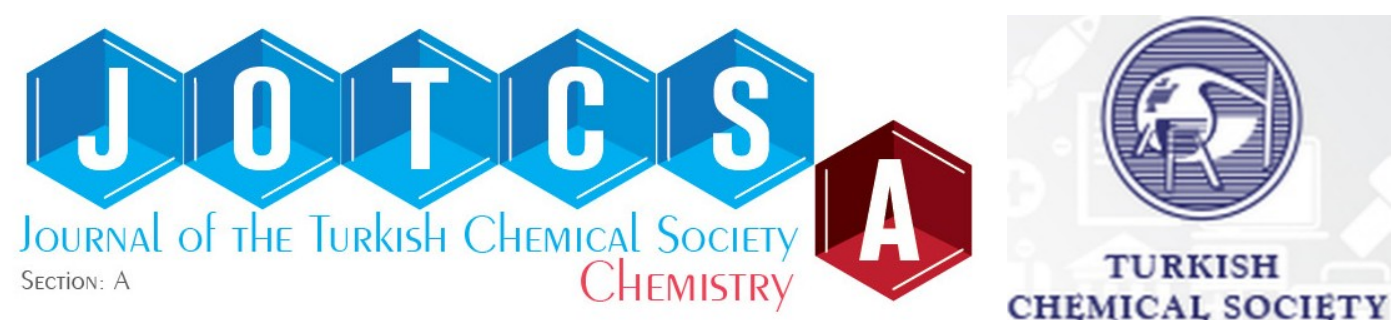

\title{
In Vitro Antioxidant Activities of Methanol Extracts of Three Achillea Species from Turkey
}

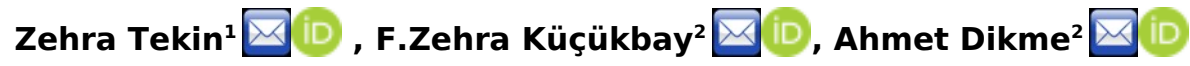 \\ ${ }^{1}$ Adıyaman University, Faculty of Pharmacy, Department of Basic Pharmaceutical Sciences, Adıyaman, \\ Turkey \\ ${ }^{2}$ Inönü University, Faculty of Pharmacy, Department of Basic Pharmaceutical Sciences, Malatya, Turkey
}

\begin{abstract}
In this study, total phenolics and flavonoid compounds of methanolic extract concentrations of three medicinal plant, Asteraceae (Compositae) L. genus that are grown in Turkey and belong to the genus Achillea, were determined with the goal of measuring their antioxidant activities. Antioxidant capacity was measured by widely used iron reducing power, DPPH radical scavenging activity and metal chelating capacity. The antioxidant activities of the achillea extracts used in the study were compared with the standard antioxidants (BHA, BHT and $\alpha$-tocopherol), which were frequently used as antioxidant food additives. According to the free radical scavenging activity antioxidant results, all the extracts exhibited higher DPPH radical scavenging activity than the standards used. The extract from A.boissieri showed remarkable 2,2-diphenyl-1-picrylhydrazyl free radical scavenging activity $\left(\begin{array}{lllll}68.51 \% & \text { at } 37.5 \mu \mathrm{g} / \mathrm{mL})\end{array}\right.$ comparable with synthetic antioxidants. The ferric reducing antioxidant power was found to be moderate in methanolic extract of Achillea species, whereas the chelating capacity of the extracts were found to be lower as compared to the standards. In addition, total phenolic, flavonoid and flavonol content of all extracts were measured spectrophotometrically and the results were expressed as "gallic acid equivalent" or "quercetin equivalent". The total phenolic content was expressed as equivalents of gallic acid and the results were observed to range from 11.86 to $23.63 \mathrm{mg} / \mathrm{g}$ dry extract weight. The total flavonoid concentrations of Achillea extracts were expressed as quercetin equivalent. Flavonoid content ranged from 15.05 to $29.70 \mathrm{mg} / \mathrm{g}$. Total flavonol concentrations of the extracts were determined to be between 5.92 and $7.20 \mathrm{mg} / \mathrm{g}$ in terms of quercetin equivalent. This study showed that Achillea L. species, which has been used for treatment in Anatolia for years, can be used as a potential natural antioxidant source.
\end{abstract}

Keywords: Phenolic content, flavonoid content, antioxidant activity, Achillea L. species

Submitted: January 28, 2021. Accepted: March 20, 2021.

Cite this: Tekin Z, Küçükbay FZ, Dikme A. In Vitro Antioxidant Activities of Methanol Extracts of Three Achillea Species from Turkey. JOTCSA. 2021;8(2):483-90.

DOI: https://doi.org/10.18596/jotcsa.867455.

*Corresponding author. E-mail: zehra.kucukbay@inonu.edu.tr.

\section{INTRODUCTION}

A free radical can be defined as any chemical species that are capable of existing with one or more unpaired outer shell electrons (1). Their high chemical reactivity due to the presence of an unpaired electron makes them highly unstable (2) and in an attempt to reach stability. The unpaired electron in a free radical can either donate an electron to or receive an electron from other molecules such as proteins, lipids, carbohydrates, and nucleic acids. This process causes damage to cell and tissue or various diseases from cardiovascular diseases to the promotion of cancer $(3,4)$. Antioxidant compounds act by controlling oxidative stress through different reaction mechanisms and may prevent the occurrence of these diseases (5).

A variety of plant materials are potential sources of natural antioxidants. A plant-based antioxidants may support the antioxidative defense (6-8). The 
genus Achillea L., comprising about 120 species, is mainly spread over the northern hemisphere. The species occur throughout Europe, Asia, China and North Africa, however its center of diversity is located in SE Europe and SW Asia. $(9,10)$ Many Achillea L. species are used for the various ailment in Turkish folk medicine due to their high nutritional value and valuable biological activities $(11,12)$.

The fact that Achillea species have a mythological history, the number of endemic species is quite high, their use among the people is widespread, and their pharmacological effects have prompted us to study these species. In our study, it was aimed to elucidate the chemical structures of the aerial parts of Achillea cretica, Achillea boissieri and Achillea nobilis subsp. spiylea collected from different locations of Turkey, which are widely used among the public, and to investigate the antioxidant effects of the species. Radical scavenging of 2,2-diphenyl1-picryl-hydrazyl (DPPH), metal chelating power and ferric reducing power assays were used to measure the antioxidant capacities of the extracts.

\section{EXPERIMENTAL SECTION}

\section{Chemicals}

All reagents were purchased from Merck (Darmstadt, Germany), Sigma-Aldrich (Steinheim, Germany), Acros Organics (Thermo Fisher Scientific, Reel, Belgium) and Fisher Scientific (Hampton, NH), while all solvents used were of analytical grade.

\section{Plant materials and extracts preparation}

A. boissieri was collected in August 2007 at the flowering period from Elbistan, between KabaktepeSariguzel, $1600 \mathrm{~m}$ altitude from Kahramanmaras Province (Turkey). The voucher specimen have been deposited in the Herbarium of Inonu University (INU) in Malatya, Turkey (INU-Collector No: TA 2594).

A. cretica L. (Asteraceae) was collected in June 2004 at the flowering period from Datça-Knidos, Muğla province, Turkey (2100 $\mathrm{m}$ above sea level). The voucher specimen has been deposited in the Herbarium of Inönü University (INU) in Malatya, Turkey (INU-Collector No: BY 15634).

A. nobilis subsp. spiylea was collected in June 2004 at the flowering period from Spil Mountain, $1100 \mathrm{~m}$ altitude from Manisa Province (Turkey). The voucher specimen has been deposited in the Herbarium of Inonu University (INU) in Malatya, Turkey (INUCollector No: BY 15750).

The aerial parts of the three Achillea L. species were dried in shade for 7 days with occasional mixing and cut into small pieces. The dried stock samples were kept in airtight containers at $4{ }^{\circ} \mathrm{C}$ for future extraction. After taking $20.000 \pm 0.001 \mathrm{~g}$ of dried plant samples prepared as described above, it was extracted with methanol using the Soxhlet extraction method until it was completely exhausted. The methanol extracts were concentrated using a rotary evaporator (Heidolph Laborota 4000, Heidolph Instruments, $\mathrm{GmbH}$ and Co, Germany) at $40{ }^{\circ} \mathrm{C}$ to obtain a viscous liquid. The concentrated extract was transferred to a $25 \mathrm{~mL}$ beaker and the remaining solvent was evaporated in the laboratory. The extracts dried after evaporation were weighed to calculate the yield and were stored at $+4{ }^{\circ} \mathrm{C}$ in a refrigerator until further analyses. The percentage yield for the extracts was as given in Table 1.

\section{Total phenolic content (TPC)}

The content of total phenolics of Achillea L. extracts was determined using Folin-Ciocalteu's reagent according to the method of Singleton et al. (13). The absorbance of reaction mixtures was measured at $765 \mathrm{~nm}$ (Shimadzu model UV-1601, Japan). The total amount of phenolic substance was calculated from the standard calibration curve prepared using the gallic acid standard, which is a phenolic compound. The results are expressed as $\mathrm{mg} \mathrm{GAE} / \mathrm{g}$ extracts on the gallic acid equivalent by using the regression equation of the curve obtained. Spectrophotometric measurements were repeated three times for each sample, and the total phenolic content was indicated by taking the average of triplicate measurements.

\section{Total flavonoid and flavonols content}

The content of total flavonoids of extracts was determined according to the procedure described by Zhishen et al. (1999) (14). Total flavonoid content of the extracts was determined spectrophotometrically according to the aluminum chloride/sodium nitrite method. Total flavonol content was determined by the method described by Yermakov et al. (1987) with minor modifications (15). Briefly, $1 \mathrm{~mL}$ of extract was mixed with $1 \mathrm{~mL}$ of $\mathrm{AlCl}_{3}(\% 2)$ and $3 \mathrm{~mL}$ of sodium acetate $(50 \mathrm{~g} / \mathrm{L})$. After $150 \mathrm{~min}$ the absorbance of the test solution was measured at $440 \mathrm{~nm}$ against blank solution. Total flavonoid/flavonol content of the extracts in certain concentration ranges was calculated according to the quercetin standard curve prepared by working in triplicate, results were expressed as $\mathrm{mg}$ of quercetin equivalent per gram dry extract.

\section{Antioxidant Activities of Achillea Extracts Antioxidant assay by DPPH radical scavenging activity \\ The 1,1-diphenyl-2-picrylhydrazyl (DPPH)} scavenging activity of Achillea L. extracts was performed according to methodology described by Blois (1958)(16). This method involves the reduction of the DPPH (2,2-diphenyl-1-picrylhydrazyl) radical with compounds that tend to give hydrogen atoms, resulting in the loss of purple color of the solution at the first moment and this ratio is based on spectrophotometric measurement of the absorbance of the solution. BHA, BHT and alpha-tocopherol were used as standards. As a control, ethanol was used. The absorbance was measured at $517 \mathrm{~nm}$ and the 
absorbance values of the samples were evaluated against the control. Free radical scavenging activity was calculated using the following equation:

$$
\% \text { Inhibition }=\left(A_{B}-A_{S / S}\right) / A_{B} \times 100
$$

$A_{B}$ is the absorbance of control and $A_{S / s}$ is the absorbance of the analyzed standard/sample.

\section{Ferric-reducing antioxidant power assay}

The reducing power, which is one of the antioxidant activity determination methods, was determined based on the method applied by Oyaizu (1986) (17). In this experiment, the yellow color turns pale green and blue, depending on the antioxidant concentration in the samples. The color produced by the reduction of $\mathrm{Fe}^{3+} \rightarrow \mathrm{Fe}^{2+}$ the change is determined by monitoring at $700 \mathrm{~nm}$. Increased absorbance of the mixture indicates stronger reducing influence of the extract.

\section{Metal chelating activity}

Metal chelating activity was determined by measuring the formation of the $\mathrm{Fe}^{2+}$-ferrozine complex according to Carter (1971)(18). The Fe(III)ferrozine method is based on the principle that $\mathrm{Fe}$ (III) forms the complex of ferrozine and Fe(III)ferrozine, and this complex reacts with antioxidants and is reduced to the magenta-colored $\mathrm{Fe}(\mathrm{II})$ ferrozine complex (absorption maximum at $562 \mathrm{~nm}$ ) (19). Therefore, the change in color was measured using a spectrophotometer against blank at $562 \mathrm{~nm}$. The percentage inhibition of ferrozine- $\mathrm{Fe}^{2+}$ complex formation was calculated as ( $A_{\text {control }}$. $\left.A_{\text {sample/standard }}\right) / A_{\text {control }} \times 100$, where $A_{\text {control }}$ is the absorbance of control reaction (without analyzed sample extract), and $A_{\text {sample }} / A_{\text {standard }}$ is the absorbance of the analyzed sample/standard. The values are presented as the mean of three measurements.

\section{RESULTS AND DISCUSSION}

The medicinal plants are huge natural sources of secondary compounds with health-promoting properties. The polyphenols derived from plants have significant antioxidant effects, which allow them to provide health benefits. Epidemiological evidence and clinical trial data obtained from in vivo and in vitro studies have shown that diets based on herbal products rich in polyphenols can reduce the risk of chronic diseases, especially cancer. Polyphenolic substances, which are named according to the number of rings and structural elements they contain, generally have a phenol ring as in phenolic acid and alcohols. More than 8000 types of polyphenols have so far been identified in nature. The four most important groups of dietary phenolics are flavonoids, phenolic acids, polyphenolic amides and other polyphenols such as curcumin in turmeric, resveratrol in red wine and 5caffeoylquinic acid in black carrot roots. Flavonoids are the largest group of plant phenols, with more than 6000 types. There are several significant groups of flavonoids, including flavonol, flavanol, isoflavon, flavon, flavanon and anthocyanin (20-22).

Phenolic acid constituents in plant kingdom are mainly divided into hydroxybenzoic acid and hydroxycinnamic acid. These compounds possess much higher in vitro antioxidant activity than wellknown antioxidant vitamins, although some of them are also regarded as anticarcinogenic $(23,24)$. Polyphenolic amides include capsaicinoids in chili peppers and avenanthramides in oats $(25,26)$. Both animal studies and laboratory studies have confirmed that phenolic amides have antioxidant activities (27-29). The species included in the genus Achillea L., which contain important bioactive components, have been used for therapeutic purposes in many parts of the world for centuries.

This study focused primarily on the determination of antioxidant activity of methanolic extract of Turkish Achillea cretica, Achillea boissieri and Achillea nobilis subsp. spiylea by in vitro methods. We measured the phenolic, flavonoid and flavonol contents in the A.cretica, $A$. boissieri and $A$. nobilis subsp. spiylea extracts we obtained.

Table 1. Analysis of main antioxidant fractions contained in A. cretica, A. boissieri and A. nobilis subsp. spiylea extracts.

\begin{tabular}{|l|l|l|l|l|}
\hline Samples & Yield (\%) & $\begin{array}{l}\text { Phenolics } \\
\text { (mg GAE/g plant } \\
\text { extract) }\end{array}$ & $\begin{array}{l}\text { Flavonoids } \\
\text { (mg QUE/g plant } \\
\text { extract) }\end{array}$ & $\begin{array}{l}\text { Flavonols } \\
\text { (mg QUE/g plant } \\
\text { extract) }\end{array}$ \\
\hline A. cretica & $0.807 \pm 0.170$ & $11.86 \pm 0.09$ & $15.05 \pm 0.17$ & $15.92 \pm 0.11$ \\
\hline A. boissieri & $5.375 \pm 0.810$ & $23,63 \pm 0.17$ & $29.70 \pm 0.03$ & $17.20 \pm 0.19$ \\
\hline $\begin{array}{l}\text { A.nobilis subsp. } \\
\text { spiylea }\end{array}$ & $7.114 \pm 1.200$ & $17.33 \pm 0.09$ & $18.20 \pm 0.03$ & $16.95 \pm 0.04$ \\
\hline
\end{tabular}

Each value is the mean \pm SD of three independent measurements. Phenolics, gallic acid equivalents; flavonoids and flavonols, quercetin equivalents.

The results (Table 1 ) showed that the $A$. boissieri extract exhibited higher total phenolics content as compared to the $A$. cretica and $A$. nobilis subsp. spiylea extracts which were approximately about $23.63 \mathrm{mg} \mathrm{GAE} / \mathrm{g}$ for $A$. boissieri extract, $11.86 \mathrm{mg}$ $\mathrm{GAE} / \mathrm{g}$ for $A$. cretica extract, and $17.33 \mathrm{mg} \mathrm{GAE} / \mathrm{g}$ for A. nobilis subsp. spiylea extract. The contents of flavonoids and flavonols were also higher in $A$. boissieri extract than in $A$. cretica and $A$. nobilis subsp. spiylea. This result clearly indicates that $A$. 
boissieri extract contains more antioxidants than the $A$. cretica and $A$. nobilis subsp. spiylea extract.

\section{Anti-oxidant effects of plant extracts}

The DPPH radical scavenging activity results are shown in Figure 1 as comparable with known antioxidants BHT and BHA. From the analysis of Figure 1 , we can conclude that the scavenging effects of $A$. cretica, $A$. boissieri and $A$. nobilis subsp. spiylea extracts on DPPH radicals were excellent, especially in the case of $A$. boissieri. The antioxidative effect of extracts studied is due to the phenolic components. Similar results were obtained earlier for the species of Achillea L. from Turkey $(30,31)$.

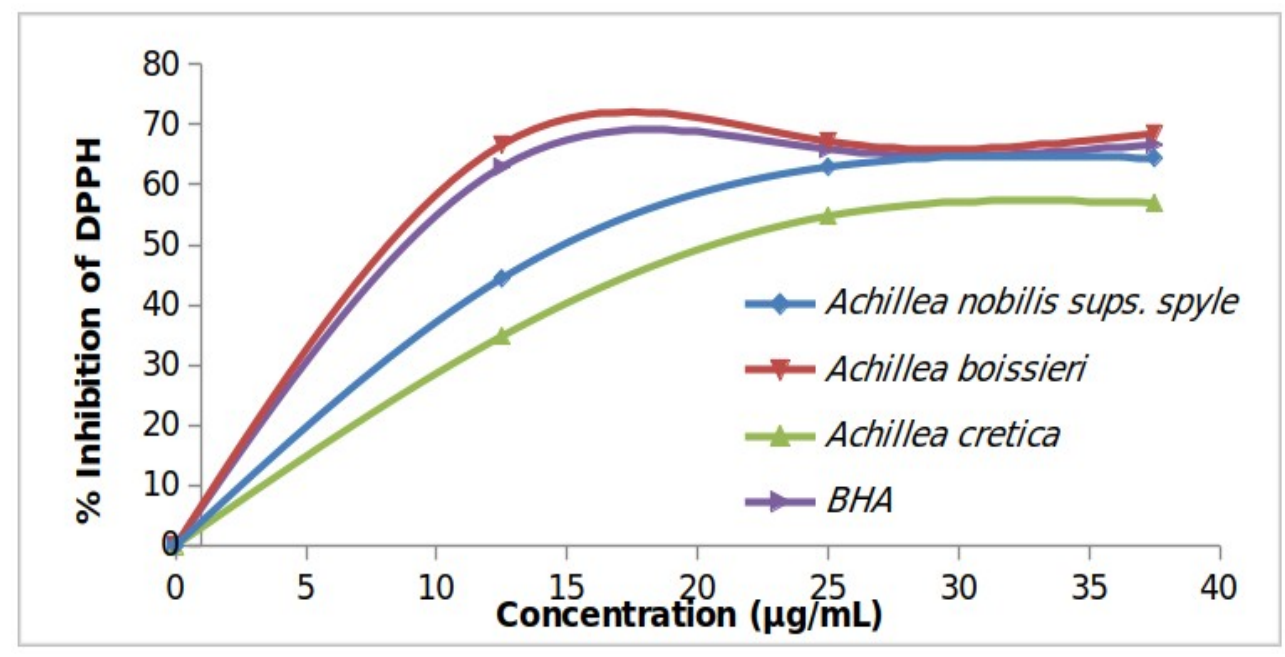

Figure 1 . Dose-dependent scavenging activity of the extracts and the standard BHA, BHT, and alphatocopherol on 1,1-diphenyl-2-picrylhydrazyl inhibition.

As described above, the antioxidants such as phenolic acids and flavonoids were present in considerable amount in the extracts of $A$. cretica, $A$. boissieri and $A$. nobilis subsp. spiylea. The prepared methanol extracts of $A$. cretica, $A$. boissieri and $A$. nobilis subsp. spiylea were compared with the standard BHA, BHT and alpha-tocopherol antioxidants. Like the radical scavenging activity, the reducing power of the extracts and standard increase with the increase in amount of the extracts from the selected plants and standard concentrations (Figure 2). At the minimum concentration of extract/standards used in this study (i.e. $5.88 \mu \mathrm{g} / \mathrm{mL}$ ), A. boissieri, $A$. nobilis subsp. spiylea, $A$. cretica and butylated hydroxyanisole (BHA) had activity values $0.111 \pm 0.001,0.102 \pm$ $0.001,0.098 \pm 0.001$ and $0.630 \pm 0.001$, respectively whereas at the highest concentration (i.e. $44.11 \mu \mathrm{g} / \mathrm{mL}$ ), the activity values of $A$. boissieri, $A$. nobilis subsp. spiylea, $A$. cretica and butylated hydroxyanisole $(\mathrm{BHA})$ were $0.343 \pm 0.001,0.229 \pm$ $0.001,0.167 \pm 0.002$ and $2.108 \pm 0.003$, respectively.

Metal chelating activities of standard antioxidants and extracts were tested at various concentrations
(12.5-125 $\mu \mathrm{g} / \mathrm{mL})$. Calculated \% inhibition values are given in Figure 3. The higher the calculated \% inhibition value, the higher the metal chelate activity was accepted and the results were evaluated. EDTA-Na $\mathrm{Na}_{2}$ was excellent chelator for ferrous ions and its chelating capacity was $94.311 \%$ at a concentration of $125 \mu \mathrm{g} / \mathrm{mL}$. BHA, alphatocopherol, $A$. cretica and $A$. nobilis subsp. spiylea did not show chelating capacity at all concentrations as well. This proves that these extracts and reference compounds have a lower capacity to chelate them with ferrous ions compared to the standard chelator EDTA. In a previous study with Achillea species, Achillea aleppica D.C. subsp. aleppica, Achillea aleppica D.C. subsp. zederbaueri (Hayek) Hub.-Mor and Achillea biebersteinii Afan. species that have compared antioxidant activity, antimicrobial activity and total phenolic amounts, it has been reported that Achillea biebersteinii Afan. species were richer than other species in terms of total phenolic. Also, Barış et al. (2011) used EDTA solution as the standard chelator in their study with Achillea species. They found that extracts in this system were not a better chelator than EDTA solution, which was a good chelator (32). 


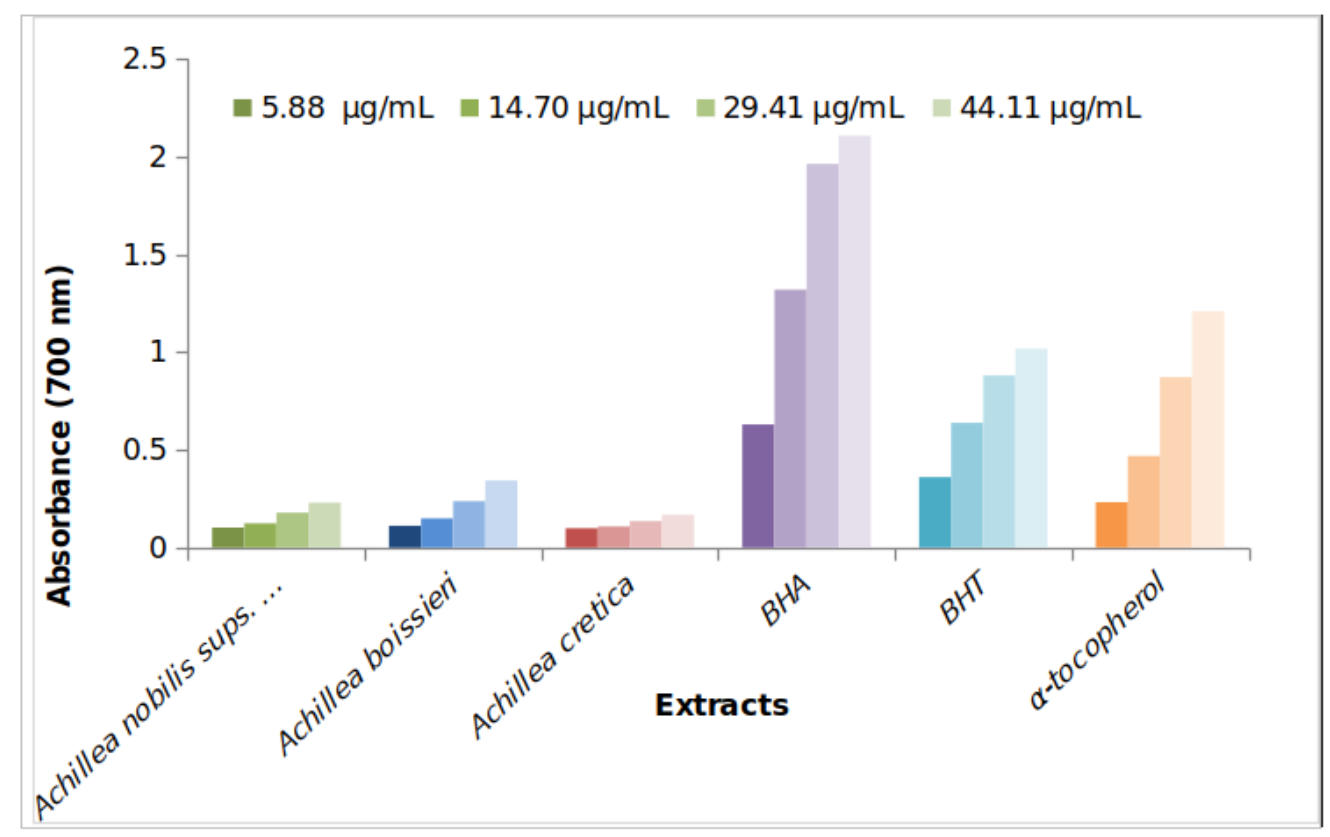

Figure 2. The reducing power of extracts and reference compounds. Values were reported as means \pm SD in triplicate.

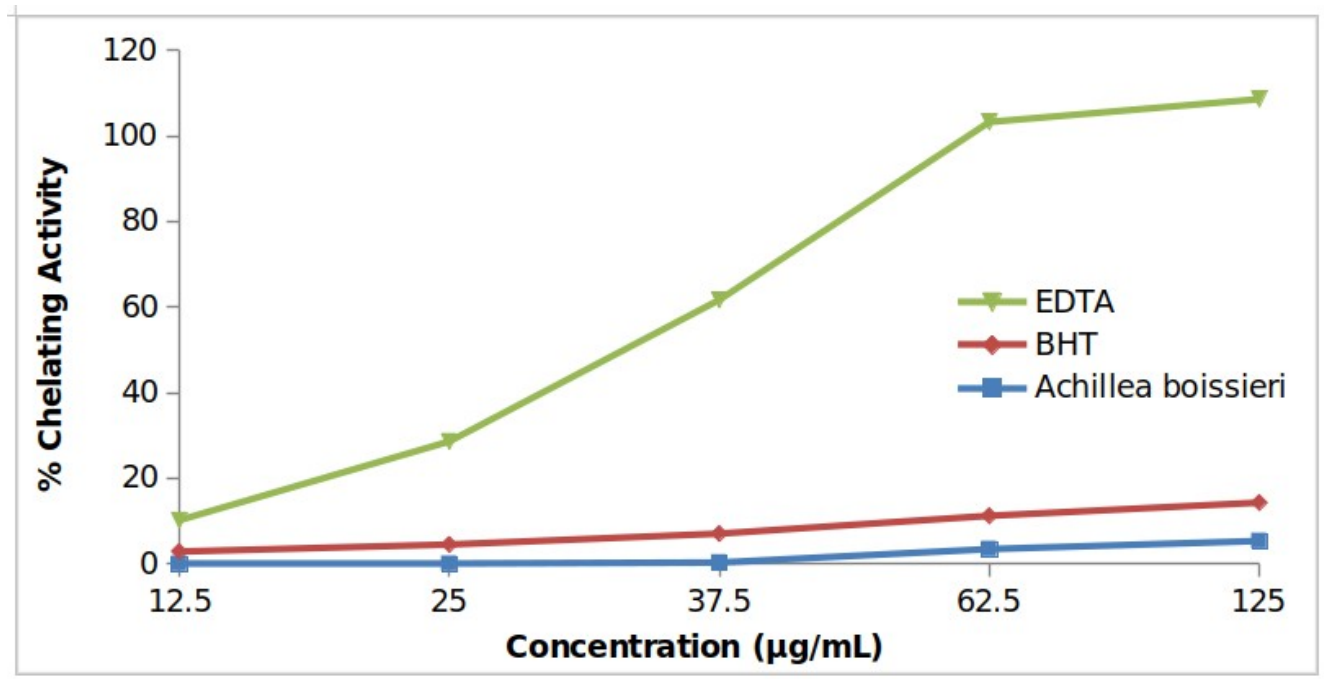

Figure 3. Metal chelating activities of Achillea extracts at different concentrations. Data are expressed as means \pm SD values $(n=3)$.

\section{CONCLUSIONS}

Achillea species have been preferred as folk remedies for various purposes for a long time. Therefore, the species named $A$. boissieri, $A$. nobilis subsp. spiylea and $A$. cretica, which spread in Turkey, were investigated in terms of antioxidant activity and amounts of phenolic/flavonoid/flavonol compound. As a result of the literature studies, no antioxidant properties were evaluated for these 3 species used in our research. Especially, the DPPH radical scavenging activities of $A$. boissieri methanol extract was determined to be higher compared to the standard used BHA and can be used as a herbal antioxidant. It is believed that the results of this study will contribute to increasing studies on the use of natural compounds in many fields, especially in food, pharmacy, medicine and natural therapy. The fact that the biological properties of the studied plant were investigated for the first time with this study increases the original value of the study. As a result, the studies conducted are very original studies in terms of this species, which has not been found before. In the following studies, isolation, purification and clarification of the structure of 
active compounds with bioactivity can be carried out.

\section{ACKNOWLEDGEMENTS}

We would like to thank Inönü University Scientific Research Projects Commission Chair for their support for the thesis with the project numbered TLO-2020-2029 as undergraduate thesis. Special thanks to Prof.Dr. Turan Arabacı for identification of the Achillea species.

\section{Conflicts of interest}

There is no potential or existing conflict of interest between our scientific work and our personal situation

\section{REFERENCES}

1. Cheeseman KH., Slater TF., An introduction to free radicals chemistry, British Medical Bulletin, 1993; 49; 48193.

2. Martínez-Cayuela M., Oxygen free radicals and human disease, Biochimie, 1995; 77; 147-61.

3. Phaniendra A., Jestadi DB., Periyasamy L., Free Radicals: Properties, Sources, Targets, and Their Implication in Various Diseases, Indian Journal of Clinical Biochemistry, 2015; 30(1); 11-26. http://doi.org/10.1007/s12291-0140446-0)

4. Rahman K., Studies on free radicals, antioxidants and cofactors, Clinical Interventions in Aging, 2007; 2(2); 219 236.

5. Devasagayam TP., Tilak JC., Boloor KK., Sane KS., Ghaskadbi SS., Lele RD., Free radicals and antioxidants in human health: Current status and future prospects, The Journal of the Association of Physicians of India, 2004; 52 ; 794-804

6. Möller P., Loft S., Dietary antioxidants and beneficial effect on oxidatively damaged DNA, Free Radical Biology and Medicine, 2006; 41; 388-415.

7. Krishnaiah D., Sarbatly R., Nithyanandam R., A review of the antioxidant potential of medicinal plant species, Food and Bioproducts Processing, 2011; 89; 217-33.

8. Katarzyna S., Anna B-K., Natalia V., Anna G-C., Sebastian G., Phenolic Composition of the Leaves of Pyrola rotundifolia L. and Their Antioxidant and Cytotoxic Activity, Molecules. 2020; 25(7); 1-16.

9. Si XT., Zhang ML., Shi QW,. Kiyota H., Chemica constituents of the plants in the genus Achillea, Chemistry \& Biodiversity, 2006; 3: 1163-1180.

10. Baser KHC., Buchbauer G., Handbook of Essential Oils: Science, Technology and Applications, Second Edition New York: CRC Press, 2015 9781466590465, p 52-53.

11. Yeşilada E., Honda G., Sezik E., Tabata M., Goto K., Ikeshiro Y., Traditional medicine in Turkey IV. Folk medicine in the Mediterranean subdivision, Journal of Ethnopharmacology, 1993; 39; 31-38.
12. Baytop T. Türkiye'de Bitkiler ile Tedavi. Phytoterapy in Turkey (2 nd Edition.), Nobel Tıp Printing Press (1999) Istanbul.

13. Singleton VL., Orthofer R., Lamuela-Raventos, RM., Analysis of total phenols and other oxidation substrates and antioxidants by means of Folin-Ciocalteu reagent, Methods in Enzymology, 1999; 299; 152-78

14. Zhishen J., Mengcheng T., Jianming W., The determination of flavonoid contents in mulberry and their scavenging effects on superoxide radicals, Food Chemistry, 1999; 64; 555-59.

15. Yermakov Al., Arasimov VV., Yarosh, NP., Methods of biochemical analysis of plants. Leningrad, Russia: Agropromizdat, 1987.

16. Blois MS., Antioxidant determinations by the use of a stable free radical, Nature, 1958; 181; 1199-200.

17. Oyaizu M., Studies on Product of Browning Reaction Prepared from Glucose Amine, Japanese Journal of Nutrition 1986; 44; 307-315.

18. Carter P., Spectrophotometric determination of serum iron at the submicrogram level with a new reagent (ferrozine). Analytical Biochemistry 1971; 40; 450-458.

19. Stookey LL., Ferrozine-A new spectrophotometric reagent for iron, Analytical Chemistry, 1970; 42(7); 779781.

20. Priyadarsini KI., The Chemistry of Curcumin: From Extraction to Therapeutic Agent, Molecules, 2014; 19(12); 20091-20112.

21. Sun Y., Qiao L., Shen Y., Jiang P., Chen J., Ye X.; Phytochemical Profile and Antioxidant Activity of Physiological Drop of Citrus Fruits, Journal of Food Science, 2013; 78(1); C37-C42.

22. Alasalvar C., Grigor JM., Zhang D., Quantick PC., Shahidi F., Comparison of volatiles, phenolics, sugars, antioxidant vitamins, and sensory quality of different colored carrot varieties, Journal of Agricultural and Food Chemistry, 2001; 49(3);1410-1416.

23. Rocha LD., Monteiro MC., Anderson JT., Anticancer properties of hydroxycinnamic acids-A Review. Cancer and Clinical Oncology, 2012; 1; 109-121.

24. Tanaka T., Tanaka T., Tanaka M., Potential Cancer Chemopreventive Activity of Protocatechuic Acid, Journal of Experimental \& Clinical Medicine, 2011; 3; 27-33.

25. Davis CB., Markey CE., Busch MA., Busch KW., Determination of capsaicinoids in habanero peppers by chemometric analysis of UV spectral data, Journal of Agricultural and Food Chemistry, 2007; 55(15); 5925-5933.

26. Boz H., Phenolic Amides (Avenanthramides) in Oats - A review, Czech Journal of Food Sciences, 2015; 33(5); 399404.

27. Peterson DM., Hahn MJ., Emmons CL., Oat avenanthramides exhibit antioxidant activities in vitro, Food Chemistry, 2002; 79; 473-478. 
28. Chen CY., Milbury PE., Kwak HK., Collins FW.,Samuel P., Blumberg JB., Avenanthramides and phenolic acids from oats are bioavailable and act synergistically with vitamin C to enhance hamster and human LDL resistance to oxidation, The Journal of Nutrition, 2004; 134; 1459-1466.

29. Hassan MH.,, Edfawy M., Mansour A., Hamed AA., Antioxidant and antiapoptotic effects of capsaicin against carbon tetrachloride-induced hepatotoxicity in rats, Toxicology and Industrial Health, 2011; 28(5); 428-438.

30. Turkoglu I., Turkoglu S., Celik S., Kahyaoglu M. Antioxidant and anti-microbial activities of Turkish endemic
Achillea species. African Journal of Microbiology Research, 2010; 4; 2034-2042.

31. Barış O., Güllüce M., Şahin F., Özer H., Kılıç H., Özkan H., Sökmen M., Özbek T., Biological activities of the essential oil and methanol extract of Achillea biebersteinii Afan. (Asteraceae), Turkish Journal of Biology, 2006; 30; 65-73.

32. Deniz B., Kızıl M., Aytekin Ç., Kızıl G., Yavuz M., Çeken B., Ertekin AS., In Vitro Antimicrobial and Antioxidant Activity of Ethanol Extract of Three Hypericum and Three Achillea Species From Turkey, International Journal of Food Properties, 2011; 14; 339-355. 
